\title{
Research Progress of Ultrafine-Grained Pure Titanium Produced by Equal-Channel Angular Pressing
}

\author{
Gu Yanxia ${ }^{1,2}, \quad$ Ma Aibin ${ }^{1}, \quad$ Jiang Jinghua ${ }^{1}, \quad$ Song Dan ${ }^{1}$ \\ ${ }^{1}$ Hohai University, Nanjing 211100, China; ${ }^{2}$ Jiangsu Maritime Institute, Nanjing 211100, China
}

\begin{abstract}
Recently, fabrication techniques of ultrafine-grained (UFG) pure titanium have been investigated to achieve enhanced performance. This paper reveals the process and properties of bulk ultrafine-grained pure titanium by equal-channel angular pressing (ECAP), with the influence of experimental parameters. Special attention is given to the deformation mechanisms via dislocation slip and twinning during ECAP. It is demonstrated that the change of microstructure in UFG Ti leads to significant enhancement of mechanical properties. Some mixed results about corrosion resistance of UFG Ti indicate the further investigations are necessary. Special emphasis is placed on the combination of ECAP and other treatments for improving overall properties. It is shown that significant enhancement has been made in UFG commercial-purity Ti after ECAP plus thermal-mechanical treatment, suggesting promising prospects of ECAP process for titanium alloys in various industries.
\end{abstract}

Key words: titanium; equal channel angular pressing (ECAP); processing parameter; deformation; properties

Severe plastic deformation (SPD) techniques can produce ultrafine-grained (UFG) alloys with superior properties by inducing large plastic deformations ${ }^{[1]}$. Equal-channel angular pressing (ECAP) is one of the few SPD technologies that have the potential of processing bulk UFG materials for commercial applications and is attracting in research and industry ${ }^{[1]}$.

The method of ECAP was introduced by Segal et al ${ }^{[2]}$, and then further developed by Valiev and his fellows in $1990 \mathrm{~s}^{[3]}$. As shown in Fig.1, the sample is pressed through the two channels of the die. When passing through the die, the sample is subjected to shear deformation at the corner of the two channels. As the original dimensions of the sample can be maintained during ECAP process, high strain and small grain size can be obtained by repeating many passes.

ECAP is used for grain refinement of many alloys, including $\mathrm{Al}, \mathrm{Mg}, \mathrm{Cu}, \mathrm{Ni}, \mathrm{Fe}$ and $\mathrm{Ti}$ alloys ${ }^{[4-9]}$. Titanium and its alloys possess the properties of high specific strength, superior corrosion resistance, lower density and excellent bio-compatibility. These excellent properties have made them one of the most important materials in aerospace, marine, automotive, and bio-medical industries. Currently, there have been a mount of reports on the producing of UFG $\mathrm{Ti}^{[10-27]}$. The production of titanium alloys by ECAP process is challenging, due to their poor deformability compared with cubic materials. Titanium and its alloys, like other hexagonal close-packed (HCP) metals, are difficultto-work materials because of limited slip systems. It is shown that titanium alloys were usually processed by ECAP at high temperatures ${ }^{[11]}$. Recently, ECAP process of commercial-purity (CP) Ti was successfully carried out at room temperature ${ }^{[20,21,23,27]}$.

\section{Experimental Factors}

The influence factors of ECAP include the channel angle $(\Phi)$, the curvature angle $(\Psi)$, the processing routes, the pressing temperature, the pressing speed, the number of passes and so on. Generally, the channel angel of the die used for the ECAP of pure titanium is $90^{\circ}$, as shown in Fig.1. Route $B_{C}$ is one of the most used ECAP process

Received date: December 25, 2016

Foundation item: Natural Science Foundation of Jiangsu Province of China (BK20131373); Fundamental Research Funds for the Central Universities (HHU2016B10314); Qing Lan Project of Jiangsu Province of China

Corresponding author: Ma Aibin, Ph. D., Professor, College of Mechanics and Materials, Hohai University, Nanjing 211100, P. R. China, Tel: 0086-25-83787239, E-mail: aibin-ma@hhu.edu.cn

Copyright (C) 2017, Northwest Institute for Nonferrous Metal Research. Published by Elsevier BV. All rights reserved. 
routes, as illustrated in Fig.2. In route $B_{C}$, the billet is rotated by $90^{\circ}$ in the same direction between consecutive passes. The ECAP process of CP-Ti is generally carried out at temperatures ranging from $623 \mathrm{~K}$ to $873 \mathrm{~K}$, which are relatively high. There are only a few studies recently reporting the produce at room temperature.

\subsection{Channel angel and curvature angle}

The channel angle and the curvature angle are referred to as $\Phi$ and $\Psi$ in Fig.1. The strain imposed on a sample in each pass depends on the channel angle. The higher the channel angle, the lower strain imposed per pass. The curvature angle has a minor effect on strain compared with the channel angle, except only for the channel angle less than $90^{\circ}$. For dies with the channel angel of $90^{\circ}$, the strain imposed to samples is close to 1 for one pass. Previous studies indicated that the most practical angles in ECAP processing of various alloys including titanium are $\Phi=$ $90^{\circ} \sim 120^{\circ}$ and $\Psi=0^{\circ} \sim 20^{\circ}$, resulting in a strain of $0.5 \sim 1.0$ approximately for a single pass ${ }^{[28]}$.

It is efficient to use an ECAP die of $\Phi=90^{\circ}$. However, it is noted that pressing billets using dies with the larger channel angle is experimentally easier for titanium, especially at relatively low temperatures. For instance, it was difficult to press CP-Ti with a $90^{\circ}$ die at room temperature because of cracking but $\mathrm{CP}-\mathrm{Ti}$ was easily pressed when the channel angle was increased to $120^{\circ}{ }^{[20]}$.

\subsection{Processing routes}

There are four pressing routes in ECAP process, as illustrated in Fig.2. There are different rotations for samples in different routes. In route A there is no rotation for billets, in route $\mathrm{B}_{\mathrm{A}}$ there is a $90^{\circ}$ rotation in alternate directions, in route $B_{C}$ there is a $90^{\circ}$ rotation in the same direction, and in route $\mathrm{C}$ there is a $180^{\circ}$ rotation $^{[1]}$. These different routes can lead to different microstructures.

V. V. Stolyarov et al. ${ }^{[11]}$ processed pure Ti by ECAP with three routes, $\mathrm{B}_{\mathrm{A}}, \mathrm{B}_{\mathrm{C}}$ and $\mathrm{C}$, for 8 passes at $450^{\circ} \mathrm{C}$. Equiaxed grains were obtained by route $B_{C}$, whereas elongated grains were obtained by routes $B_{A}$ and $C$. $B_{A}$ was the least effective route in grain refinement, while $B_{C}$ was the most effective route. However, the UFG Ti produced by route $\mathrm{B}_{\mathrm{C}}$ did not show better mechanical properties than routes $B_{A}$ and $C$.

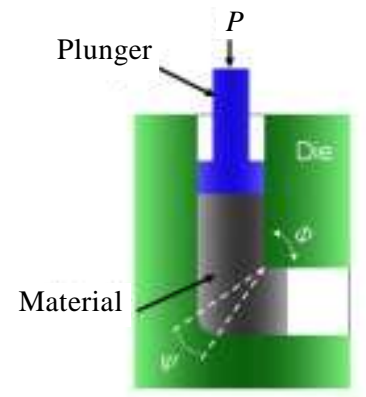

Fig.1 Schematic of ECAP ( $\Phi$ : the channel angel, $\psi$ : the curvature angle)
Zhernakov et al. ${ }^{[13]}$ studied two ECAP routes of CP-Ti, i.e. route $B_{C}$ and route $C$. It was shown that the UFG Ti produced by route $B_{C}$ indicated better homogeneity than route $C$. Although the main grain sizes were similar through two different routes, the ECAP process by route $\mathrm{B}_{\mathrm{C}}$ led to the formation of a larger fraction of high-angle grain boundaries. Nanostructures provided an increase of strength and cycle endurance, and the increase was especially attainable by route $B_{C}$.

Raab et al. ${ }^{[19]}$ carried out ECAP of CP $\mathrm{Ti}$ at a lower temperature $\left(300^{\circ} \mathrm{C}\right)$ by the following pressing routes: route $\mathrm{A}$, route $\mathrm{B}_{\mathrm{C}}$ and $\mathrm{C}$, with a $120^{\circ}$ die. The results demonstrated that ECAP of $\mathrm{CP}$ Ti by routes $\mathrm{B}_{\mathrm{C}}$ and $\mathrm{C}$ at $300{ }^{\circ} \mathrm{C}$ enabled to produce equiaxed UFG structure. ECAP by route $\mathrm{A}$ did not allow to process equiaxed ultrafine grains.

It is confirmed from the results above the important role of processing routes on microstructure refinement and mechanical properties improvement via ECAP pressing.

\subsection{Pressing temperature}

ECAP processing is easier at elevated temperatures. However, there are two trends as the temperature increases. First, there is an increase in grain size of the ECAPed sample. Second, there is a decrease in the fraction of high-angle grain boundaries of the ECAPed sample.

For pure $\mathrm{Ti}$, processing is usually conducted at temperatures from $473 \mathrm{~K}$ to $873 \mathrm{~K}$. Tests showed that decreasing temperature during ECAP from $300^{\circ} \mathrm{C}$ to $200^{\circ} \mathrm{C}$ resulted in the formation of finer equiaxed ultrafine grain structure $^{[19]}$. There were several attempts on ECAP of CP-Ti at room temperature (RT). Early experiment conducted by Semiatin et al. ${ }^{[29]}$ showed the pure Ti billet processed by ECAP at RT broke into pieces by segmentation. Afterwards, Zhao et al. ${ }^{[20]}$ showed that pure Ti can be processed by ECAP for a single pass at RT with the larger channel angle $\left(120^{\circ}\right)$ and a slower pressing speed $\left(0.5 \mathrm{~mm} \cdot \mathrm{s}^{-1}\right)$. Moreover, the material processed by one pass at room temperature exhibited even slightly better mechanical
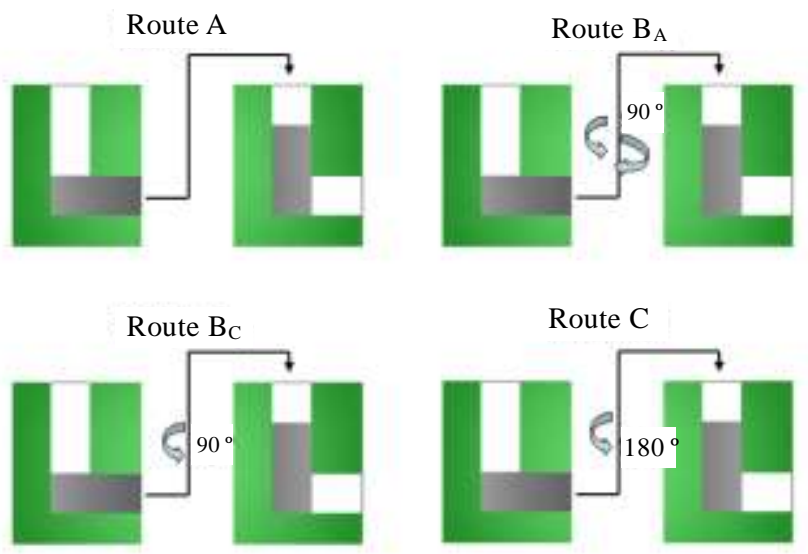

Fig.2 Processing routes of ECAP 
properties than that produced by multiple passes at relatively elevated temperatures. Later on, CP-Ti was processed up to 8 passes at RT using a $120^{\circ}$ die with ultrafine grains $\sim 200 \mathrm{~nm}{ }^{[21,23]}$. Samples were also successfully processed by 2 passes using an $135^{\circ} \mathrm{die}^{[25]}$. Recently, Zhao et al. ${ }^{[27]}$ processed CP-Ti successfully up to 4 ECAP passes at RT using a $90^{\circ}$ die. It is worth mentioning that in the ECAP processing the billets were rotated by $180^{\circ}$ between two passes (route C) to minimize the flow stresses. A special composite lubricant was also applied. Equiaxed grains of $\sim 150 \mathrm{~nm}$ were attained.

There is a change in the deformation mechanism during ECAP process conducted at room temperature in comparison to the ECAP at elevated temperature and it will be discussed in detail in Section 3.

\subsection{Pressing speed}

Tests on titanium showed that there were hardly any differences in microstructure of the samples pressed by one pass at 0.2 and $2.8 \mathrm{~mm} \cdot \mathrm{s}^{-1[30]}$. Nevertheless, it is essential to conduct processing at a slower speed for CP-Ti because titanium alloys are hard-to-deform materials and there might be some cracking in the billet at the faster speed ${ }^{[25]}$. The pressing speed for CP-Ti is usually in $0 \sim 6 \mathrm{~mm} \cdot \mathrm{s}^{-1}$.

The pressing speed can also influence the deformation mechanism of CP-Ti during ECAP. Experiment showed that as the pressing speed decreased from $2.8 \mathrm{~mm} \cdot \mathrm{s}^{-1}$ to 0.8 $\mathrm{mm} \cdot \mathrm{s}^{-1}$, the deformation mechanism transited from twinning to dislocation slip ${ }^{[30]}$.

\subsection{Number of passes}

ECAP process can introduce increasing strain with the increase of passes, leading to remarkable grain refinement. The microstructure evolution of UFG Ti after 1, 2, 4 and 8 ECAP passes were investigated by Chen et al. ${ }^{[24]}$. After 1 pass, there was a mixed microstructure with elongated grains, twins, as well as fine grain bands. The microstructure was further fined after 2 passes. The fraction of elongation was reduced significantly and the fraction of equiaxed ultrafine grains was increased. After 4 passes, most grains were ultrafine and equiaxed, and most grain boundaries were high angle. The grains were more homogeneous after 8 passes. Conclusions are drawn that grain refinement mainly occurs during the first pass, and the efficiency decreases gradually during the following passes.

Previous studies show that all of the experimental parameters affect microstructural refinement significantly during the ECAP processing. It is important to recognize that optimized microstructural homogeneities and mechanical properties in CP-Ti can be achieved by the combination and quantification of the parameters in ECAP processing.

\section{Deformation Mechanisms}

Slip is generally believed to be the main way of grain refinement mechanism in $\mathrm{Al}, \mathrm{Cu}, \mathrm{Ni}$ alloys and other fcc and bcc materials. However, the deformation mechanism of titanium alloys is suggested different because there are limited slip systems in hcp metals. Slip are primarily on $\{10 \overline{1} 0\},\{10 \overline{1} 1\}$ and $\{11 \overline{2} \overline{2}\}$ planes in titanium alloys, which are called a slip and $\mathbf{a}+\mathbf{c}$ slip $^{[16]}$. Besides dislocation slips, various deformation twins were observed during deformation of the $\mathrm{CP}-\mathrm{Ti}^{[10,16]}$. So it is believed that twinning plays an important role in the deformation of CP-Ti during ECAP. Previous studies reported that in $\mathrm{CP}-\mathrm{Ti}$, the twinning planes were $\{10 \overline{1} 2\},\{10 \overline{2} 1\}$ and $\{11 \overline{2} 2\}$ at ambient temperatures, while the twinning plane was $\{10 \overline{1} 1\}$ at temperatures above $673 \mathrm{~K}^{[16]}$. Nevertheless, plenty of evidence confirmed that $\{10 \overline{1} 1\}$ twinning was the primary deformation mechanism of CP-Ti processed by ECAP at various temperatures $(523 \sim 673 \mathrm{~K})^{[10,14,15]}$.

Kim et al. ${ }^{[10]}$ conducted a microstructure examination on CP-Ti processed by one pass of ECAP at $623 \mathrm{~K}$ and proved the formation of twins. Transmission electron microscope (TEM) micrograph ${ }^{[16]}$ showed the appearance of elongated parallel bands. The selected area diffraction patterns of the region indicated that the twin plane was $\{10 \overline{1} 1\}$. This result was contrast to the previous investigation that deformation twinning on $\{10 \overline{1} 1\}$ planes was preferred at temperatures above $673 \mathrm{~K}$. Therefore, deformation mode of twinning during ECAP differs with that in conventional process. High Resolution Electron Microscope (HREM) image analyses revealed that various twinning modes such as the $b_{1}, b_{2}$ and $b_{3}$ modes involved in accommodating the deformation of titanium during ECAP process ${ }^{[15]}$.

Pressing temperature affects the deformation mechanism significantly. A single ECAP at various temperatures from $473 \mathrm{~K}$ to $873 \mathrm{~K}$ was conducted on $\mathrm{CP}-\mathrm{Ti}^{[14]}$. The results revealed that titanium pressed at $473 \mathrm{~K}$ was composed of thin parallel shear bands resulted from slip. However, samples processed at temperatures above $523 \mathrm{~K}$ were composed of $\{10 \overline{1} 1\}$ parallel deformation twinning bands. The twin density increased with temperature and the highest twin density was obtained in the sample processed at $623 \mathrm{~K}$; after that, the twin density decreased at higher temperatures. This nonlinear temperature dependency of the $\{10 \overline{1} 1\}$ twinning is suggested to be the consequence of a high strain state during ECAP pressing.

During the second pass, however, titanium was observed to deform mainly by dislocation slip ${ }^{[16]}$. The system of slip was strongly related to the pressing route. For route A, basal a slip and micro-twins played a major role in deformation. For route B, the main mechanism was prism a slip. For route $\mathrm{C}$, deformation mechanism was characterized by prism $\mathbf{a}$ and $\mathbf{c}+\mathbf{a}$ dislocations. These differences were resulted from the resolved shear stress of different slip systems and the texture that formed during the first pass.

Microstructure investigation of $\mathrm{CP}-\mathrm{Ti}$ processed by 
ECAP for 3 and 4 passes has been conducted by Chen et al. ${ }^{[22]}$. The results showed that during 3 and 4 passes, the deformation is mainly dislocation slip. There were no $\{10 \overline{1} 1\}$ twins but $\{10 \overline{1} 2\}$ twins were detected, indicating that even though the dominant deformation during the $3 \mathrm{rd}$ and 4th passes is dislocation slip, the twinning has also contributed to accommodate part of the deformation. However, the reason for $\{10 \overline{1} 2\}$ twins instead of $\{10 \overline{1} 1\}$ twins is not clear. Therefore, further study on this phenomenon is needed.

Although the first pass of ECAP-Ti at elevated temperature $(623 \mathrm{~K})$ is dominated by $\{10 \overline{1} 1\}$ twinning, the mechanism of deformation for CP-Ti during ECAP may be different at room temperature from that at elevated temperatures. There are several studies on the microstructure evolution of CP-Ti after 1-2 passes at RT. Studies by Zhao et al. ${ }^{[20]}$ showed that $\{10 \overline{1} 1\}$ twins were found in the samples processed by ECAP for one pass at RT.

Microstructure observation was conducted on pure $\mathrm{Ti}$ after pressing by ECAP at RT through 1 and 2 passes with a channel angle of $135^{\circ}{ }^{[25]}$. Microstructure by TEM showed the appearance of three types of slip: basal slip, prismatic slip and pyramidal slip, as well as $\{10 \overline{1} 2\}$ twinning.

Novel deformation structures of CP-Ti after ECAP at RT have been studied using electron back scattered diffraction (EBSD) by Chen et al. ${ }^{[26]}$ and the results indicated that the major deformation mechanism is twinning during the first ECAP pass. Besides, all the four types of twins, $\{10 \overline{1} 1\}$, $\{10 \overline{1} 2\},\{11 \overline{2} 2\}$ and $\{11 \overline{2} 1\}$ have occurred in the same original grain, which is much different from the twins formed at elevated temperatures.

Although there are several papers on the deformation mechanism (including slip and twinning) of CP-Ti after ECAP, but data are only given in states after a single pass, 2 passes, during pass 3/4. Reports on the deformation mechanism after 4 passes are really rare. Moreover, the evolution of deformation as the number of passes increases needs to be further studied.

\section{Properties Achieved Using ECAP}

\subsection{Strength and ductility}

It is shown that the strength of CP-Ti was improved by ECAP process. It is worth noting that $\mathrm{CP}-\mathrm{Ti}$ pressed by a single pass of ECAP at RT exhibits comparative strength with that pressed at elevated temperature up to multiple passes $^{[20]}$. The result is provoking that it opens up a new way to perform ECAP process for titanium alloys which saves energy and time significantly, as well as reduces the damage to the mould and extends the service life of the mould.

Strength and ductility usually show an inverse relationship. Therefore, materials are rarely both strong and ductile. CP-Ti processed by ECAP has a relatively lower ductility than the unprocessed counterparts. Thus, studies of obtaining both high strength and ductility in ECAP processed UFG materials are of great interest. Strategies to improve ductility in the ultrafine-grained $\mathrm{CP}-\mathrm{Ti}$ are discussed below.

One approach is increasing the pass number of ECAP. Further straining of CP-Ti at room temperature from 1 to 8 passes of ECAP increases both strength and ductility simultaneously ${ }^{[23]}$. It is believed that the proportion of high-angle grain boundaries can be increased by the addition of strain and this grain boundary structure promotes sliding and rotation of grain boundaries, resulting in enhanced ductility ${ }^{[1]}$.

Another approach was suggested through the low temperature annealing. It is shown that low temperature annealing of UFG CP-Ti produced by HPT led to enhanced strength and ductility ${ }^{[18]}$. Annealing at $300^{\circ} \mathrm{C}$ for $10 \mathrm{~min}$ resulted in a $30 \%$ increase in strength and increased ductility. It is suggested that during annealing at $300{ }^{\circ} \mathrm{C}$ for $10 \mathrm{~min}$, recovery process took place, while significant grain growth did not occur and an ordering of dislocations near grain boundaries was observed. These structural changes of grain boundaries are considered to be contributed to the high strength and ductility. It is also found that annealing process of UFG Ti produced by ECAP and thermal-mechanical treatment (TMT) led to unusual enhancement of both strength and ductility ${ }^{[31]}$. It was suggested to be associated with ordering of grain boundaries and impurity segregation at grain boundaries.

In conclusion, combination of enhanced strength and relatively good ductility could be obtained in UFG CP-Ti by ECAP process.

\subsection{Fatigue behavior}

The total fatigue life can be divided into two regions: crack nucleation region and crack propagation region ${ }^{[1]}$. In the stage of crack nucleation, the resistance requires strength. While in the crack propagation region, the tolerance to crack propagation requires ductility. Thus, the advanced fatigue properties are dependent on high strength and relatively good ductility.

Fatigue performance of UFG CP-Ti processed by ECAP was investigated by Vinogradov et al. ${ }^{[12]}$. The average grain size of ECAPed CP-Ti was $300 \mathrm{~nm}$. The fatigue limit was $380 \pm 5 \mathrm{MPa}$, which was dramatically higher than coarsegrained (CG) Ti (225 MPa) ${ }^{[12]}$.

There is another investigation verifying the increase of the high-cycle fatigue life of UFG CP-Ti ${ }^{[32]}$. The fatigue limit of CP-Ti increased from $210 \mathrm{MPa}$ to $350 \mathrm{MPa}$ after ECAP process. However, the ECAPed $\mathrm{Ti}$ shows higher notch sensitivity.

Fatigue properties of UFG titanium can be significantly improved by additional thermal treatment ${ }^{[33]}$. CP-Ti Grade 4 produced by ECAP was subjected to thermal-mechanical 
treatment. The equiaxed grains of about $150 \mathrm{~nm}$ were obtained. The fatigue limit of UFG CP-Ti increased from 350 to $590 \mathrm{MPa}$ after processing by ECAP and TMT. Furthermore, additional annealing increased the fatigue limit to $610 \mathrm{MPa}$.

It is reasonable to conclude that the achievement of high strength and ductility via ECAP can result in significant improvement of fatigue properties of titanium. But the optimum processing schemes are still needed to be investigated.

\subsection{Corrosion resistance}

Previous results showed that grain size has an effect on corrosion resistance among different alloy systems ${ }^{[34-41]}$. As for titanium alloys, there are wide scattering results from the related reports, varying from the higher ${ }^{[34,37,39,41]}$ to the lower $^{[36]}$ corrosion resistance, along with no significant difference ${ }^{[38]}$ of ultrafine-grained and coarse-grained CP-Ti alloys.

It was reported that ECAP after 8 passes improved the corrosion resistance of $\mathrm{CP}-\mathrm{Ti}$ in $\mathrm{H}_{2} \mathrm{SO}_{4}$ and $\mathrm{HCl}$ solutions from $1 \mathrm{~mol} / \mathrm{L}$ to $5 \mathrm{~mol} / \mathrm{L}^{[34]}$. It is believed that the improved corrosion resistance is associated with the rapid formation of passive layers at grain boundaries and defects. Furthermore, the impurity segregation to grain boundaries in coarse-grained $\mathrm{Ti}$ is responsible for the accelerated corrosion. However, the results from another report go against the above observations. It has been found in $0.9 \%$ $\mathrm{NaCl}$ solution that the corrosion resistance of UFG Ti produced by hydrostatic extrusion was slightly lower ${ }^{[36]}$. The grain size had no influence on the thickness of oxide film on the surface of pure Ti. In comparison to UFG Ti, the passive films on the surface were more homogeneous in CG Ti.

Texture affects the corrosion behavior of titanium significantly. Hoseini et al. ${ }^{[37]}$ investigated the corrosion resistance of $\mathrm{CP}-\mathrm{Ti}$ with different grain sizes and crystal orientations. Unexpectedly, the maximum corrosion resistance appears at the sample processed by 2 passes. It is shown from inverse pole figures that most basal (0002) planes were parallel to the surface in samples processed by 2 passes. While most orientation lies between (1120) and (10 $\overline{10})$ planes in the 0,4 , and 8 passed samples. The results demonstrate that in titanium the basal plane exhibits better corrosion behavior compared with other planes. As the 2-pass samples did not exhibit the smallest grain size, it is noted that texture is dominant in the factors that affect the corrosion behavior of CP-Ti.

Afterwards, Kim et al. ${ }^{[39]}$ reported that the UFG $\mathrm{Ti}$ exhibited enhanced corrosion resistance in $\mathrm{H}_{2} \mathrm{SO}_{4}$ and $\mathrm{HCl}$ solutions. The samples with the smallest grain size and most intense basal texture revealed the highest corrosion resistance.

Annealing treatment has been reported to improve the corrosion resistance of $\mathrm{UFG} \mathrm{Ti}^{[40]}$. The improvement is considered to be associated with the texture orientation transformation during annealing and the reduction of defects and residual stress.

In addition, investigations indicated that ECAP processed UFG Ti showed improved corrosion behavior in comparison with the CG counterparts in simulated body fluid ${ }^{[41]}$.

The results demonstrate that the corrosion properties of UFG CP-Ti depend strongly on the processing method, structure, annealing state, material purity and corrosion solution, and further investigations is needed in this respect.

\section{Combination Processes}

It has been demonstrated that the combination of ECAP and further thermal-mechanical treatments, including extrusion, cold rolling and drawing, can be utilized for significant improvement of mechanical properties and additional grain refinement of CP-Ti. The yield and ultimate strength of UFG $\mathrm{Ti}$ was increased to 1020 and $1050 \mathrm{MPa}$, respectively, by combining ECAP and cold rolling process ${ }^{[17]}$, which were higher than Ti-6Al-4V alloy.

The studies suggest that the ECAP+TMT process can produce UFG titanium alloys with high strength comparable to Ti-6Al-4V alloys for structural and medical applications.

\section{Summary}

In recent years, ECAP process has revealed a rapid development. Currently, it is commonly used to improve overall properties of $\mathrm{CP}$-Ti through grain refinement. It is shown that all the experimental parameters play important roles on microstructure and properties of materials during ECAP. A variation of ECAP processing conditions allows designers to make choice flexibly among the strength, ductility, fatigue performance, corrosion resistance and other properties according to the expected applications. The deformation mechanisms in the UFG titanium has been developed though microstructure evolution. There are a few topics remaining to be studied in detail, for instance, the formation mechanism of twinning at different temperatures, evolution of twinning after multi-pass ECAP, the corrosion resistance in different environment. Future research need to be expanded on the application of UFG CP-Ti in other areas that are not just confined to aerospace and medical industries. There is great potential that UFG Ti processed by ECAP would develop extensively in modern research and commercialization.

\section{References}

1 Valiev R Z, Langdon T G. Prog Mater Sci[J], 2006, 51: 881

2 Segal V M. Mater Sci Eng A[J], 1995, 197: 157

3 Valiev R Z. Mater Sci Eng A [J], 1997, 234-236: 59

4 Ma A, Suzuki K, Nishida Y et al. Acta Mater[J], 2005, 53: 211 
5 Ma A B, Nishida Y, Suzuki K et al. Scripta Materialia[J], 2005, 52: 433

6 Ma A, Jiang J, Saito N et al. Mater Sci Eng A[J], 2009, 513-514: 122

7 Liu Z, Bai S, Zhou X et al. Mater Sci Eng A[J], 2011, 528: 2217

8 Song D, Ma A B, Jiang J H et al. Corr Sci [J], 2011, 53: 362

9 Yuan Y, Ma A, Jiang J et al. Mater Sci Eng A[J], 2013, 588: 329

10 Kim I, Jeong W-S, Kim J et al. Scripta Mater[J], 2001, 45: 575

11 Stolyarov V V, Theodore Zhu Y, Alexandrov I V et al. Mater Sci Eng A [J], 2001, 299: 59

12 Vinogradov A Y, Stolyarov V V, Hashimoto S et al. Mater Sci Eng A [J], 2001, 318: 163

13 Zhernakov V S, Latysh V V, Stolyarov V V et al. Scripta Mater[J], 2001, 44: 1771

14 Kim I, Kim J, Shin D H et al. Mater Sci Eng A[J], 2003, 342: 302

15 Kim I, Kim J, Shin D H et al. Scripta Mater[J], 2003, 48: 813

16 Shin D H, Kim I, Kim J et al. Acta Mater[J], 2003, 51: 983

17 Stolyarov V V, Zhu Y T, Alexandrov I V et al. Mater Sci Eng $A[\mathrm{~J}], 2003,343: 43$

18 Valiev R Z, Sergueeva A V, Mukherjee A K. Scripta Mater[J], 2003, 49: 669

19 Raab G I, Soshnikova E P, Valiev R Z. Mater Sci Eng A[J], 2004, 387-389: 674

20 Zhao X, Fu W, Yang X et al. Scripta Mater[J], 2008, 59: 542

21 Yang X R, Zhao X C, Fu W J. Rare Metal Materials and Engineering $[\mathrm{J}], 2009,38(5): 0955$

22 Chen Y J, Li Y J, Walmsley J C et al. Mater Sci Eng A[J], 2010, 527: 789

23 Zhao X, Yang X, Liu X et al. Mater Sci Eng A[J], 2010, 527.
6335

24 Chen Y J, Li Y J, Walmsley J C et al. Scripta Mater[J], 2011, 64: 904

25 Zhang Y, Figueiredo R B, Alhajeri S N et al. Mater Sci Eng $A[\mathrm{~J}], 2011,528: 7708$

26 Chen Y J, Li Y J, Xu X J et al. Mater Lett [J], 2014, 117: 195

27 Zhao X, Yang X, Liu X et al. Mater Sci Eng A[J], 2014, 607: 482

28 Roodposhti P S, Farahbakhsh N, Sarkar A et al. Transactions of the Nonferrous Metals Society of China[J], 2015, 25: 1353

29 Semiatina S L, DeLob D P. Mater Des[J], 2000, 21: 311

30 Kim I, Kim J, Shin D H et al. Phys Met Mater Sci[J], 2003, 34A: 1555

31 Semenova I, Salimgareeva G, Da Costa G et al. Adv Eng Mater[J], 2010, 12: 803

32 Kim W J, Hyun C Y, Kim H K. Scripta Mater[J],, 2006, 54: 1745

33 Semenova I P, Valiev R Z, Yakushina E B et al. J Mater Sci $[\mathrm{J}]$, 2008, 43: 7354

34 Balyanov A, Kutnyakova J, Amirkhanova N A et al. Scripta Mater[J], 2004, 51: 225

35 Mishra R, Balasubramaniam R. Corr Sci[J], 2004, 46: 3019

36 Garbacz H, Pisarek M, Kurzydlowski K J. Biomolecular Engineering [J], 2007, 24: 559

37 Hoseini M, Shahryari A, Omanovic S et al. Corr Sci[J], 2009, 51: 3064

38 Mendes Filho A A, Rovere C A, Kuri S E et al. Revista Matéria[J], 2010, 15: 254

39 Kim H S, Yoo S J, Ahn J W et al. Mater Sci Eng A[J], 2011, 528: 8479

40 Kim H S, Kim W J. Corr Sci[J], 2014, 89: 331

41 Maleki H, Hajizadeh K, Hadjizadeh A et al. Mater Sci Eng $C[\mathrm{~J}], 2014$, 39: 299

\title{
等通道转角挤压法制备超细晶纯钛的研究进展
}

\author{
谷艳霞 ${ }^{1,2}$, 马爱斌 ${ }^{1}$, 江静华 ${ }^{1}$, 宋 丹 $^{1}$ \\ (1. 河海大学, 江苏 南京 211100) \\ (2. 江苏海事职业技术学院，江苏 南京 211100)
}

\begin{abstract}
摘 要: 近年来, 围绕超细晶纯钛的制备及其性能提升方面开展了许多研究。本文综述了制备超细晶纯钣块材的等通道转角挤压工艺 (ECAP)及其重要参数, 分析了挤压过程中纯钛的位错滑移及孪晶变形机制。超细晶纯钛的强度、塑性、抗疲劳性能显著提高, 而耐蚀 性测试结果呈多样性, 有待进一步研究。等通道转角挤压和后续热机械处理的结合, 可进一步提高超细晶纯钛的综合性能, 表明采用 ECAP 技术制备的超细晶纯钛在各行各业有着广阔的发展前景。
\end{abstract}

关键词: 钛; 等通道转角挤压 (ECAP); 工艺参数; 变形; 性能 